\title{
Low heat flow from young oceanic lithosphere at the Middle America Trench off Mexico
}

\author{
Timothy A. Minshull ${ }^{\mathrm{a}, *}$, Rafael Bartolomé ${ }^{\mathrm{b}}$, Siobhán Byrne ${ }^{\mathrm{a}}$, Juanjo Dañobeitia ${ }^{\mathrm{c}}$ \\ ${ }^{a}$ Southampton Oceanography Centre, European Way, Southampton SO14 3ZH, UK \\ ${ }^{\mathrm{b}}$ Unidad de Tecnologia Marina-CSIC, Centro Mediterraneo de Investigaciones Marinas y Ambientales (CMIMA), Barcelona, Spain \\ "Instituto de Ciencias de la Tierra "Jaume Almera" (CSIC), Barcelona, Spain
}

Received 8 October 2004; accepted 6 May 2005

Available online 28 September 2005

Editor: R.D. van der Hilst

\begin{abstract}
Seismic reflection profiles across the Middle America Trench at $20^{\circ} \mathrm{N}$ show a high amplitude bottom simulating reflector interpreted as marking a phase transition between methane hydrate and free gas in the pore space of both accreted and trench sediments. We determine the depth of the hydrate-gas phase boundary in order to estimate the geothermal gradient and hence the heat flow beneath the trench and the frontal part of the accretionary wedge which overlies the downgoing plate. After correction for sedimentation, heat flow values in the trench and through the accretionary wedge are only about half of the values predicted by plate cooling models for the 10 Ma subducting lithosphere. There is no systematic correlation between heat flow in the accretionary wedge and distance from the trench. A comparison with heat flow predicted by a simple analytical model suggests that there is little shear heating from within or beneath the wedge, despite the high basal friction suggested by the large taper angle of the wedge. The geothermal gradient varies systematically along the margin and is negatively correlated with the frontal slope of the wedge. Some local peaks may be attributed to channelised fluid expulsion.
\end{abstract}

(C) 2005 Elsevier B.V. All rights reserved.

Keywords: heat flow; accretionary wedge; gas hydrate; BSR; hydrothermal circulation; subduction zone

\section{Introduction}

The conductive heat flow within an accretionary wedge is controlled by several competing processes $[1,2]$. Frictional heating within and at the base of the wedge will cause a landward increase in heat flow, while sediment thickening will cause a landward decrease. Channelised fluid escape may lead to local anomalies in the thermal gradient, while pervasive po-

\footnotetext{
* Corresponding author. Tel.: +44 2380 596569; fax: +44 2380 593052.

E-mail address: tmin@soc.soton.ac.uk (T.A. Minshull).
}

rous flow may cause a systematic increase in geothermal gradient and hence apparent heat flow in the uppermost part of the sediment column. In principle, some of these parameters may be estimated by matching numerical models to an observed heat flow pattern.

Conventional heat flow probe surveys sample the thermal gradient in the upper few metres of the sediment column and at isolated points. Such measurements can be susceptible to transient changes in bottom water temperature. Methane gas hydrates are stable within the top few hundred metres of ocean floor sediments in deep water adjacent to continental margins. The temperature and pressure conditions of the phase boundary marking the base of 
this stability zone is now relatively well known. In addition, the decomposition of hydrate immediately beneath the phase boundary commonly results in the formation of free gas $[3,4]$, resulting in a readily identifiable high amplitude seismic "bottom simulating reflection" (BSR) which follows local isotherms, cross-cuts sedimentary reflectors and may be mapped over large areas. Close to continental margins, determination of the depth to this reflector allows average geothermal gradients between the seabed and the BSR to be measured over wide areas [5]. Here we estimate conductive heat flow through sediments overlying young oceanic crust subducted beneath the western margin of Mexico at $20^{\circ} \mathrm{N}$, based on observations of a strong and continuous BSR in multichannel seismic reflection (MCS) profiles acquired during the Crustal Offshore Research Transect by Extensive Seismic Profiling (CORTES) experiment [6].

\section{Tectonic setting}

North of the Rivera Fracture Zone, the young oceanic Rivera plate is subducting beneath the Jalisco

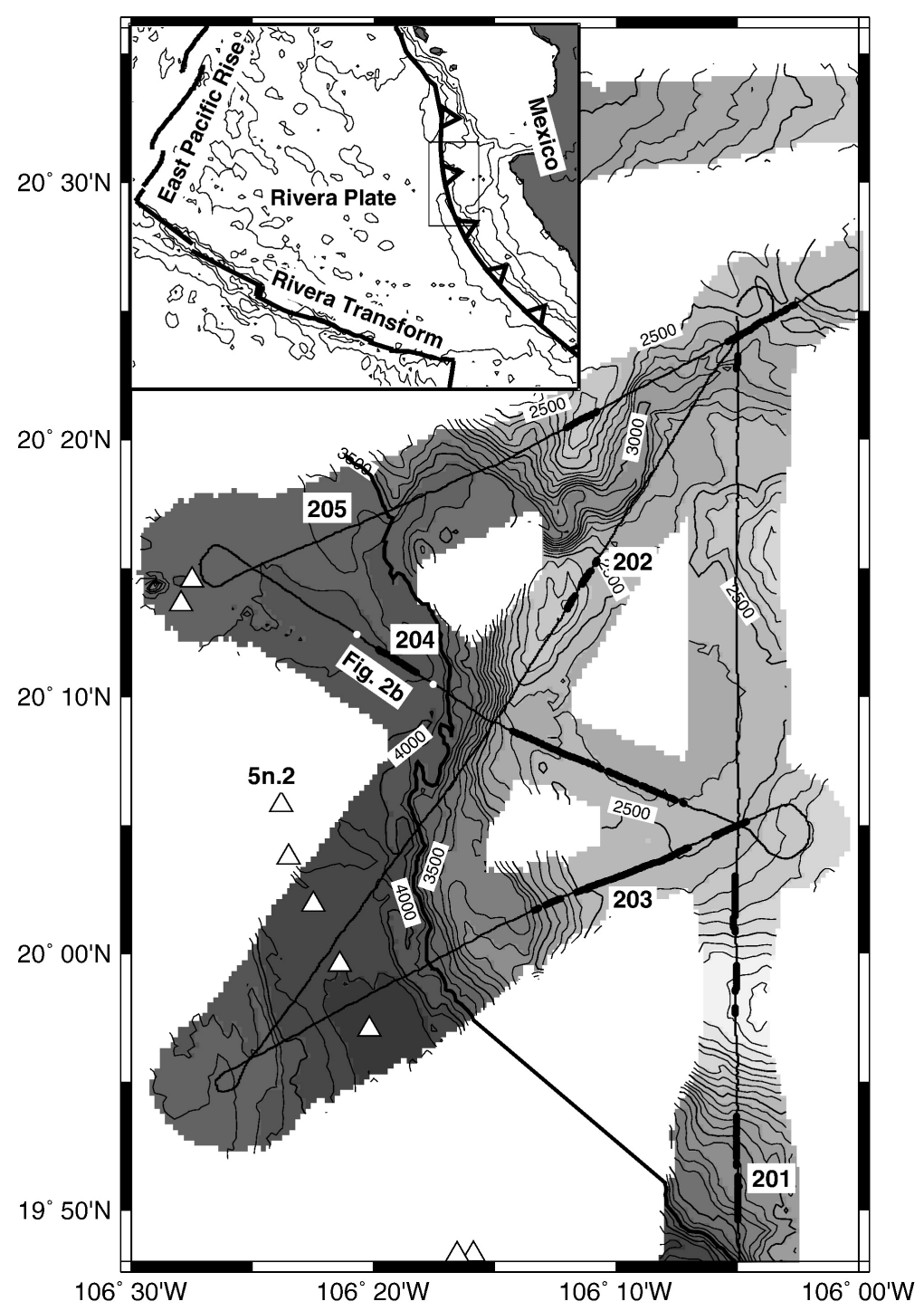

Fig. 1. Swath bathymetric data from the Middle America Trench at $20^{\circ} \mathrm{N}$. Thin lines labelled 201-205 mark multichannel seismic reflection profiles. Filled circles mark BSR picks used in heat flow calculations. Thick line marks approximate location of the toe of the accretionary wedge, traced along the $3800 \mathrm{~m}$ contour in the south of the survey area and the $3600 \mathrm{~m}$ contour in the north, and interpolated across gaps in swath coverage. Open triangles mark picks of magnetic anomaly 5n.2 [8]. White circles mark portion of line 204 show in Fig. 2b. Inset shows plate tectonic setting and bathymetric contours at $1000 \mathrm{~m}$ intervals with box marking the area of the main figure. 
Block of western Mexico, which is generally considered as part of the North American plate, but may have some degree of independent motion [7,8] (Fig. 1). Well-documented magnetic anomalies on the Rivera and Pacific plates allow the plate tectonic history of the region to be reconstructed in considerable detail since $10 \mathrm{Ma}$ [8], though the geometry of plates subducted before 2 Ma remains controversial [9]. The convergence rate at the Middle America Trench has fluctuated strongly during this time, and decreased to zero between 2.5 and 1 Ma. Local earthquake data indicate a Benioff zone dipping at around $10^{\circ}$ to 20 $\mathrm{km}$ depth, then steepening to $50^{\circ}$ at $40 \mathrm{~km}$ depth [10].

Whilst extensive seismic work and deep drilling have been conducted on the subducting Cocos plate to the south of the Rivera Fracture Zone (e.g., [11]), the Rivera-North America convergent margin has received much less attention. During the CORTES experiment, a grid of MCS profiles was acquired across this margin in a $\sim 50 \times 50 \mathrm{~km}$ region around $20^{\circ} \mathrm{N}$, offshore Puerto Vallarta (Fig. 1). Here the mean convergence rate since $1 \mathrm{Ma}$ is $30 \mathrm{~mm} / \mathrm{yr}$. Spreading rates at the Pacific-Rivera spreading centre have fluctuated over the past $10 \mathrm{Ma}$ between intermediate and fast rates; the lithosphere currently entering the subduction zone here appears to have formed at a full spreading rate of around $97 \mathrm{~mm} / \mathrm{yr}$ [8].

MCS data were acquired using a 10-airgun source array fired at $30 \mathrm{~s}$ intervals (approximately $75 \mathrm{~m}$ ) and a 96-channel, $2.4 \mathrm{~km}$ hydrophone steamer. Airgun shots were also recorded on nine ocean bottom seismometers (OBSs) deployed within the region of Fig. 1, and swath bathymetric data were acquired simultaneously with seismic data. Bathymetric data reveal a complex accretionary wedge morphology, with a steep slope at the toe of the wedge and a more gentle slope further landward. There is also considerable relief on the Rivera plate seaward of the trench. Seismic velocity models based on the OBS data indicate a dip of $8-12^{\circ}$ for the subducting oceanic plate [6], consistent with the initial dip of the Benioff zone further landward [10]. The top of oceanic basement may be traced for about $10 \mathrm{~km}$ beneath the accretionary wedge, and the Rivera plate is covered by about $1 \mathrm{~km}$ of sediments as it enters the subduction zone. Over much of the survey area, BSRs may be identified as high-amplitude, reversed-polarity reflectors subparallel to the seabed (Figs. 1-3). The high amplitude and reversed polarity (Fig. 2) confirm that these reflectors are due to a hydrate-free gas phase boundary. On one profile (Fig. 3b) the BSR is evident at

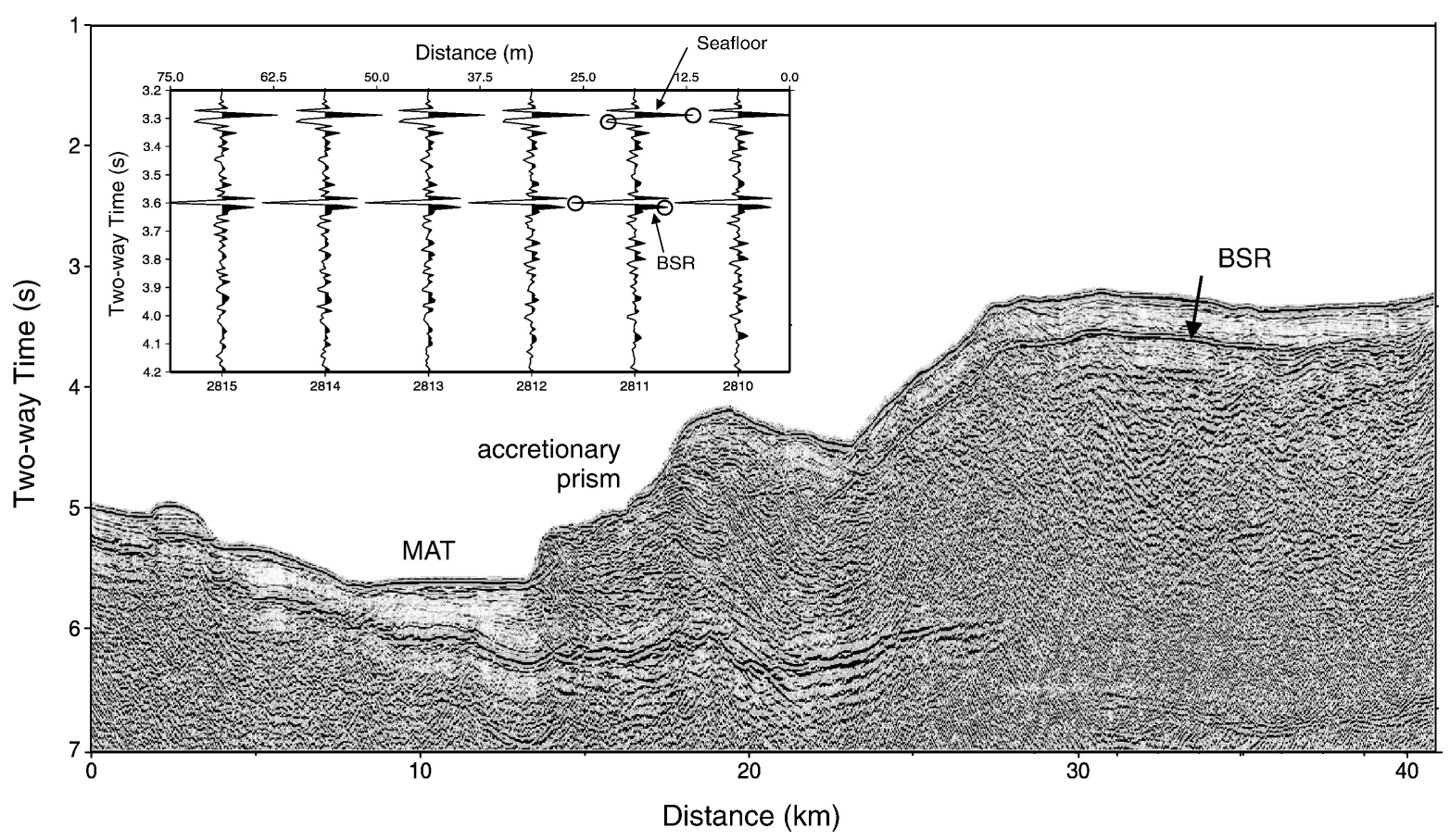

Fig. 2. Example seismic reflection profile (line 203) showing oceanic basement entering the trench and a thickening accretionary wedge with a clear BSR 200-300 m below the seabed. Data processing includes a pre-stack bandpass filter (5-9-58-62.5 Hz), a near-trace mute to attenuate multiples, minimum phase predictive deconvolution, velocity analyses at least every $2.5 \mathrm{~km}, \sim 16$-fold stack, Kirchhoff time migration, automatic gain control (AGC) with a 1-s window and trace mixing for display. Inset shows (without AGC) the high amplitude and reversed polarity of the BSR. 


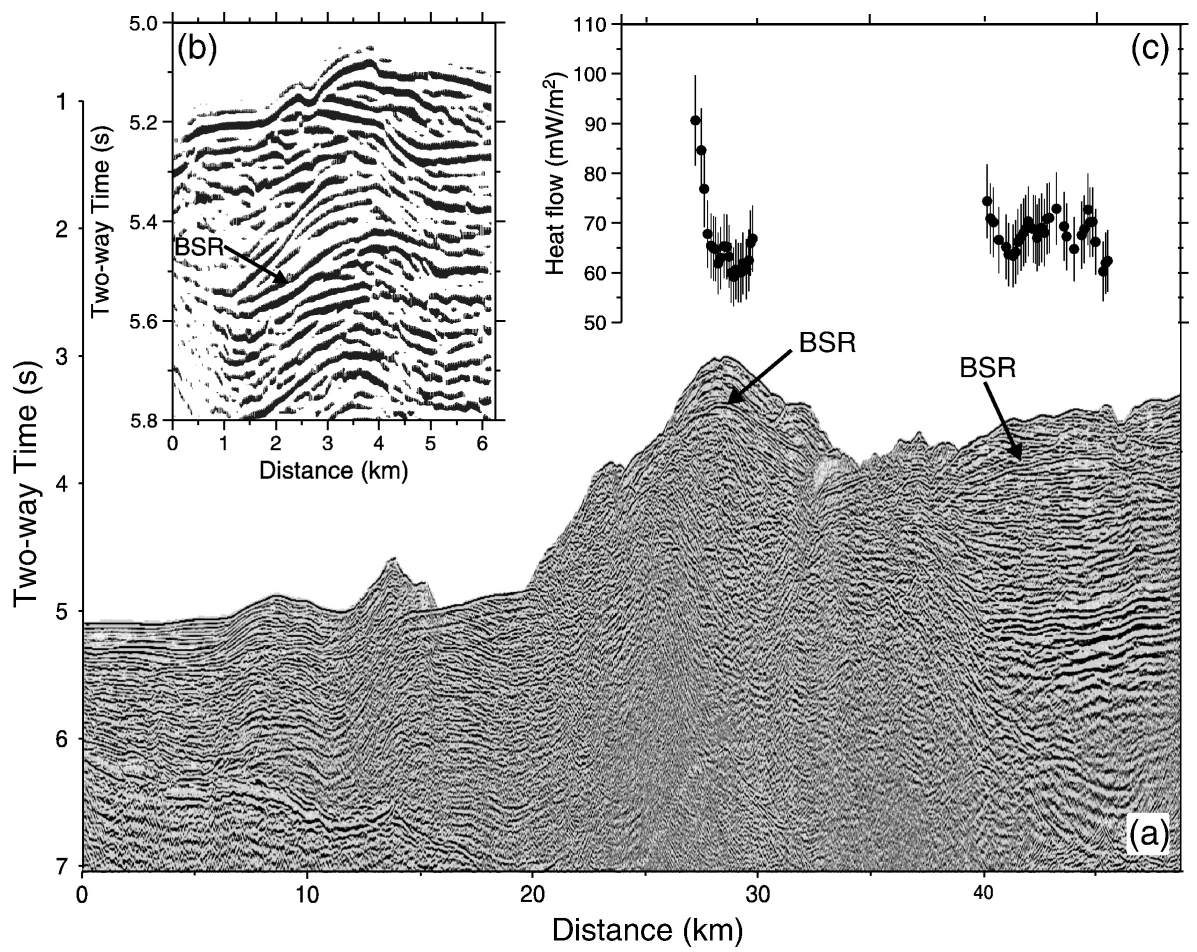

Fig. 3. a) Migrated seismic reflection profile (line 205) showing BSR with variable depth below the seafloor. Processing is as for Fig. 2. b) Blow-up of a portion of line 204 where the BSR may be traced seaward of the toe of the wedge. c) Inferred heat flow values along this profile, using the method described in the text. Note the high values indicating fluid escape near a probable thrust fault (which is not well imaged) at $\sim 26 \mathrm{~km}$.

the toe of the accretionary wedge and a few kilometres beyond in the Middle America Trench.

\section{Heat flow}

Heat flow was estimated from BSR depths following an approach first developed by Yamano et al. [5] and reviewed in detail in [12]. BSR picks were made only where the reflector depth could be readily picked; in some parts of the survey area a BSR was clearly present, but strong interference from sedimentary reflectors made picking difficult. For depth conversion, a seismic velocity function was developed for the uppermost $1 \mathrm{~s}$ of the sediment column by compiling interval velocities from stacking velocities (estimated by semblance analysis). Velocities computed in this way have considerable uncertainty, so we do not expect to resolve accurately lateral variations. A straight-line regression to these data yielded a velocity in $\mathrm{km} / \mathrm{s}$ given by $v=1.4481+0.4069 T$, where $T$ is the two-way time in seconds beneath the seabed, with a scatter around this line of up to $\sim 20 \%$. Using this velocity function, the depth of each BSR pick was computed, and hence the pressure at the BSR, assuming that the sediments are sufficiently permeable for hydrostatic pressures to be maintained. Since the depth calculation involves an integration of the velocity function, errors are reduced to perhaps half the scatter of the velocity data. A comparison between this function and results of detailed velocity analysis in one area of the survey suggests that velocities in the hydrate stability zone may be systematically underestimated by perhaps as much as $\sim 10 \%$ because the regression includes underlying low velocity zones where free gas is present. Hence our calculated heat flow values may be over-estimated by a similar amount.

The pressure may then be related to temperature using a parameterisation of the hydrate-free gas phase boundary. The empirical fit to experimental data of Dickens and Quinby-Hunt [13] is based entirely on data below $15 \mathrm{MPa}$, whereas our data come entirely from hydrostatic pressures greater than $15 \mathrm{MPa}$. Therefore, rather than extrapolating this empirical fit, we use phase boundaries based on a theoretical model tuned to experimental data up to $\sim 40 \mathrm{MPa}$ [14]. These curves match the data of [13], but diverge from their empirical fits by $2-3{ }^{\circ} \mathrm{C}$ in the at the temperatures and pressures of interest here (Fig. 4).

We have no data on the composition of the gas or the salinity of the pore water; we assume that the gas 


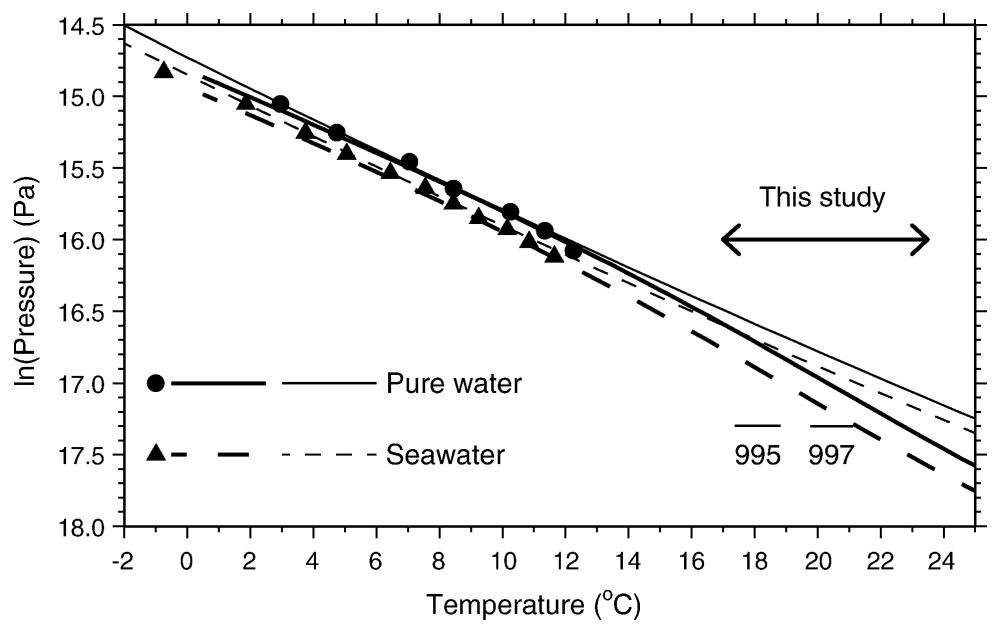

Fig. 4. Circles and triangles are measurements of the hydrate/free gas phase boundary for pure methane with pure water and seawater, respectively, to $\sim 12{ }^{\circ} \mathrm{C}$ [13]. Thin solid and dashed lines are empirical fits to these data [13]. Thick solid and dashed lines are phase boundaries predicted by the theoretical approach of Tohidi et al. [14] Here seawater is approximated by $560 \mathrm{mMol} \mathrm{NaCl}$ solution, and the dashed curve shown, which is the one used in this study, matches closely the seawater curve of [16]. Arrows mark the range of inferred temperatures at the BSR in our study area. Thin horizontal bars mark error bounds on estimates of the temperature of the phase boundary from in situ measurements at ODP Sites 995 and 997 on Blake Outer Ridge [35].

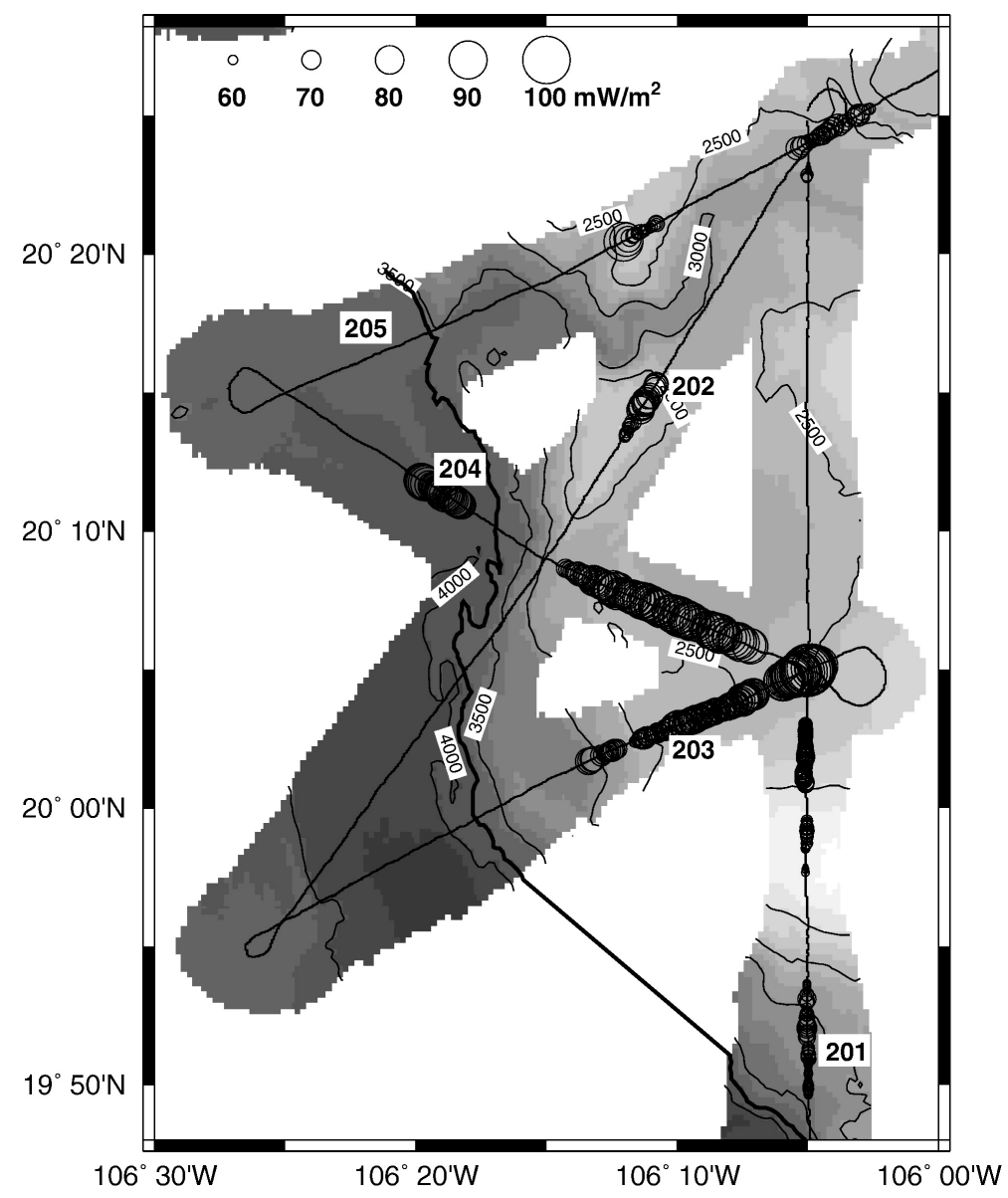

Fig. 5. Bathymetry (as in Fig. 1) with heat flow values. Each heat flow estimate is marked by a circle with diameter linearly related to the value as indicated by the key. Thick line marks the toe of the accretionary wedge. 
is predominantly methane with concentrations of other gases which are too small to significantly change the phase boundary; this assumption appears to hold in similar tectonic settings worldwide. Hyndman et al. [15] concluded that in situ data favour a base of the hydrate stability field controlled by the pure methane/pure water phase boundary. However, other authors (e.g., $[12,16]$ ) have favoured the pure methane/seawater boundary, and this boundary better fits the data from recent Ocean Drilling Program (ODP) legs [12] (Fig. 4). The remaining discrepancies between the computed phase boundary and ODP calibrations may be explained by capillary effects in fine-grained sediments [16]. These effects are expected to be minor on the case of the western Mexico margin, where the predominant sediment input is likely to turbidites. Therefore in this study we use the pure methane-seawater phase boundary. A $1{ }^{\circ} \mathrm{C}$ uncertainty in the phase boundary corresponds to a $5 \%$ uncertainty in the inferred heat flow. From the temperature and depth of the BSR and the seafloor temperature, the mean geothermal gradient in the interval above the BSR may be computed. The seafloor temperature was computed from a 3 rd order polynomial fit to water column temperature data from the digital NOAA World Ocean Atlas; the resulting temperature varies little from $2{ }^{\circ} \mathrm{C}$ across the entire area where BSRs were observed.
A significant source of uncertainty in the heat flow calculation is the thermal conductivity of the sediments, which can vary widely in marine sediments. No in situ data are available for our survey area, and borehole data show a scatter of $+/-20 \%$ or more in thermal conductivity for unconsolidated sediments at a given depth in the upper $500 \mathrm{~m}$ of the sediment column in similar accretionary wedge settings $[12,17]$. We could have used a depth-dependent value that accounted for compaction by relating the conductivity to seismic velocity (following [18]), but have instead used a constant value as suggested by [12], since the predicted variation with depth is small. In the absence of nearby direct measurements of thermal conductivity, we used a value of 1.05 $\mathrm{W} / \mathrm{m} / \mathrm{K}$, which falls at the centre of the range of empirical velocity-conductivity curves compiled in [18] for the velocity range above the BSR and is typical of values measured in accretionary wedge sediments $[12,17]$. The uncertainty in the resulting heat flow values is at least $10 \%$ and may be larger [12].

The resulting heat flow values vary between 52 and $105 \mathrm{~mW} / \mathrm{m}^{2}$, with a mean value across the survey area of $73 \mathrm{~mW} / \mathrm{m}^{2}$. The heat flow varies significantly over relatively short distances along individual profiles, and shows no clear correlation with distance from the toe of the accretionary wedge (Figs. 5 and 6). The most landward values, in the north-east corner of the survey area, are amongst the lowest observed, but the highest

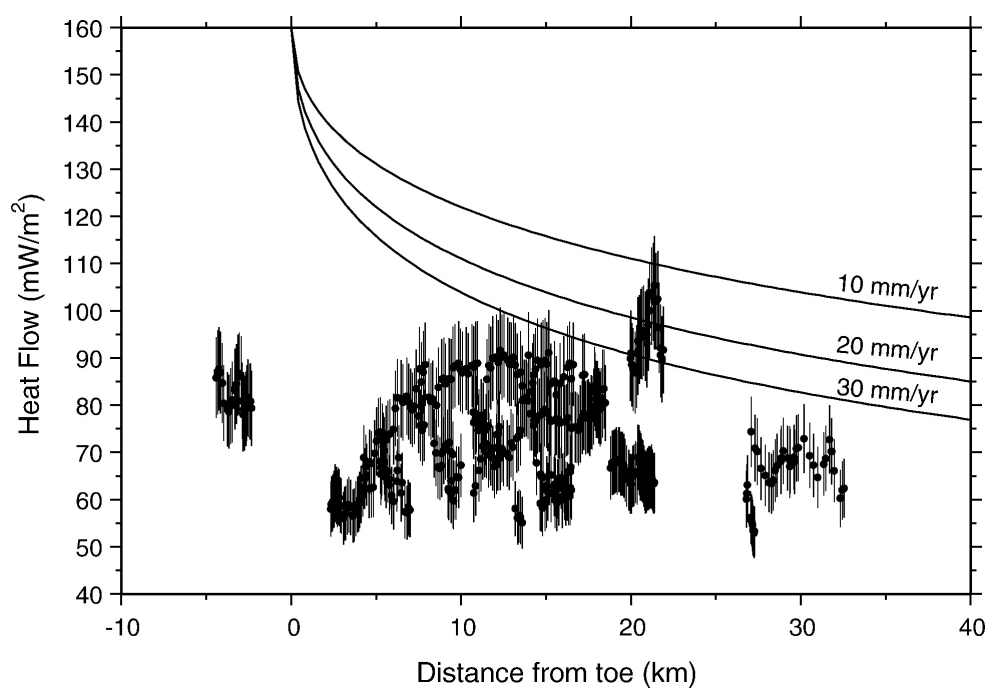

Fig. 6. Variation of inferred heat flow with distance from the toe of the accretionary wedge, as defined by the thick line in Fig. 1. Error bars correspond to a likely minimum uncertainty of $\pm 10 \%$. Solid lines mark predicted heat flow using the model of Molnar and England [29] with a decollement dip of $10^{\circ}$ beneath the accretionary wedge, a thermal thermal diffusivity of $10^{-6} \mathrm{~m}^{2} / \mathrm{s}$ and the convergence rates as labelled. Frictional heating and radiogenic heat production from accretionary wedge sediments are both neglected; these would increase further the predicted heat flow. The decollement beneath the wedge is not clearly imaged by reflection profiles. The calculation assumes that the decollement follows the top of the oceanic crust, as appears to be the case at the toe of the wedge, where the entire sediment column appears to be deformed (Fig. 2). The convergence rate has been $\sim 30 \mathrm{~mm} / \mathrm{yr}$ since $1 \mathrm{Ma}$, but may have been much lower prior to $1 \mathrm{Ma}$ (see text). 
values are also observed towards the landward edge of the survey. Near the trench, values are in the range 55$88 \mathrm{~mW} / \mathrm{m}^{2}$. There are no historical heat flow probe data which are close enough for meaningful comparisons to be made.

\section{Discussion}

The calculated heat flow values are surprisingly low. Based on magnetic anomaly lineations [8], the oceanic lithosphere entering the Middle America Trench at the latitude of our survey is aged around 10 Ma. Plate cooling models $[19,20]$ would predict heat flow of $\sim 160 \mathrm{~mW} / \mathrm{m}^{2}$ for this age lithosphere. The mean observed value for this age lithosphere is $80-90 \mathrm{~mW} / \mathrm{m}^{2}$ $[20,21]$, and the difference from conductive models is commonly attributed to the effects of hydrothermal circulation. Heat flow studies at the Juan de Fuca Ridge have shown that, where the oceanic crust is covered with a few hundred metres of sediment, heat flow values return to values consistent with plate cooling models within about $20 \mathrm{~km}$ of basement outcrops, suggesting that a relatively thin sediment cover can isolate the hydrothermal system from the open ocean [22]. However, our observed values are low despite the relatively thick sediment cover. Sedimentation itself causes a reduction in heat flow. However, correction using standard curves [23], which assume that sediments are shales with a seabed porosity of $60 \%$ and a compaction constant of $1.54 \mathrm{~km}$, would increase the trench values by $<20 \%$ to $65-105 \mathrm{~mW} / \mathrm{m}^{2}$. This correction is appropriate for heat flow values measured at the seabed, and is likely to over-correct BSR-derived values, so the heat flow from basement in the trench remains unusually low.

Low heat flow values from young oceanic lithosphere off Costa Rica [24] have been attributed to the presence of a hydrothermal system which is still connected to the ocean through normal faults created by flexure of the downgoing plate. Young oceanic lithosphere is relatively weak and therefore is likely to bend readily over relatively short wavelengths in response to loading by the downgoing slab, promoting such faulting. Faults attributed to plate bending and penetrating to $18-20 \mathrm{~km}$ depth have been imaged in 14-24 Ma lithosphere off Costa Rica and Nicaragua [25]. In our survey area, fault blocks are clearly imaged in the oceanic basement beneath the trench (Figs. 2, 3), and the overlying sediment column appears to be intensely faulted. The significant variations in heat flow over distances of a few kilometres in the trench (Figs. 5, 6) are consistent with the presence of a convective system, with higher values near zones of fluid discharge. However, elsewhere in similar circumstances, such as off Oregon [26], the conductive heat flow is similar to that predicted by plate cooling models. A recent global compilation has shown that conductive heat flow near trenches is not systematically lower than in crust of the same age away from trenches and does not appear to decrease as lithosphere approaches trenches [27]. Conductive heat flow is also unusually low over a broad area of the Cocos plate well away from the trench [28], so perhaps additional permeability due to slab bending is not required. Unfortunately there are insufficient heat flow data available seaward of the region of plate flexure to test whether the heat flow in our survey area is indeed depressed by enhanced hydrothermal cooling.

The heat flow through the accretionary wedge in principle provides information about frictional heating within and beneath the wedge [2,29]. In the absence of frictional heating, tectonic thickening of the sediment column, as observed in seismic reflection data (Figs. 2, 3 ), is expected to result in a rapid decrease in heat flow landward of the trench. This effect is particularly strong if sediment thickening is rapid [2]. However, an approximate conductive model $[29,30]$ would predict heat flow values higher than those observed across the wedge, even if a high-end estimate of the thickening rate is used and frictional heating is neglected (Fig. 6). Also, tectonic thickening cannot explain the low heat flow at and seaward of the toe of the wedge.

The thermal time constant for a $6 \mathrm{~km}$ oceanic crust is only $\sim 100 \mathrm{kyr}$. Hence even if hydrothermal cooling in the trench extends throughout the crust, one would expect a conductive geotherm to be re-established within a few kilometres of the trench if tectonic thickening seals the hydrothermal system from the ocean. The observed low heat flow may indicate that heat exchange continues between the ocean and the subducted crust, or alternatively that the subducting lithosphere is hydrothermally cooled to much greater depth. For example, the thermal time constant for $20 \mathrm{~km}$ of lithosphere is $>1$ Myr, so if faults extended as deep in our survey area as off Costa Rica and Nicaragua [25] and hydrothermal cooling reached similar depths, a conductive geotherm would be reestablished only several tens of kilometres landward of the trench.

Whatever the thermal structure of the plate entering the subduction zone, the observed heat flow pattern also appears to preclude significant frictional heating, which would result in a landward increase in observed values $[2,29]$. This result is consistent with observations further south on the Mexican margin, where values de- 
crease rapidly landward [31,32]. Conversely, the application of critical taper theory [33] would suggest high basal friction since the wedge angle is large. Both the conductive heat flow calculation and the critical taper analysis may be oversimplifications here since they assume a constant convergence rate: convergence between the Rivera plate and the Jalisco block may have restarted very recently after a period without significant relative motion [8].

The accretionary wedge morphology appears to vary significantly along the margin. In the north (line 205), there is a steep frontal scarp. In the centre of the survey area (lines 202-204) the slope at the toe of the wedge is more gentle. In the south (line 201) there is a steep scarp again. These changes in morphology may indicate that the three regions are in different phases of the accretionary cycle, with recent underthrusting and frontal erosion in the north and south and ongoing frontal accretion in the centre [34]. There are signs of a corresponding systematic along-margin variation in heat flow, with lower heat flow in the north and the south and higher heat flow in the centre of the survey area. The variation may indicate that sediment underthrusting dominates the thermal regime in the north and south but is less significant in the centre.

Some of the large local variations observed may be linked to channelised fluid expulsion (Fig. 3), since in some cases heat flow reaches a local maximum over inferred thrust faults, as observed commonly elsewhere in accretionary wedges [e.g., 18,26]. However, the accreted sediments are sufficiently deformed that it is generally difficult to identify such faults.

\section{Conclusions}

1. The conductive heat flow through the upper 200 $300 \mathrm{~m}$ of sediments overlying $10 \mathrm{Ma}$ oceanic lithosphere entering the Middle America Trench at $20^{\circ} \mathrm{N}$ is $55-88 \mathrm{~mW} / \mathrm{m}^{2}$. There is no systematic change in heat flow landward of the trench, where values of $52-105 \mathrm{~mW} / \mathrm{m}^{2}$ are observed.

2. After correction for sedimentation, the conductive heat flow is about half of the conductive value expected for $10 \mathrm{Ma}$ lithosphere; the reduced value can be explained by hydrothermal circulation. This circulation may be enhanced by normal faulting in the downgoing slab, or may just be unusually active in the Rivera plate, as it is in the adjacent Cocos plate.

3. In the accretionary wedge, where the hydrothermal system is likely to be sealed, heat flow remains low for several tens of kilometres landward of the trench, despite the high basal friction that would be required to maintain the current wedge taper.

4. The heat flow varies systematically along-strike within the wedge, and this heat flow variation may be correlated with variations in wedge morphology. Where the wedge has a steep frontal scarp, heat flow values landward of the scarp are low, while where the frontal scarp is shallow, heat flow values are higher.

\section{Acknowledgements}

This work was initiated during a study visit of TAM to Barcelona funded through the Royal Society/CSIC bilateral agreement. We thank the captains and crews of the $R / V_{\mathrm{S}}$ Hespérides, Altair and Humboldt for their support during the experiment, and the Mexican authorities for facilitating work within their exclusive economic zone. Data acquisition was supported by the CICYT project ANT94-0182-C02-01/02 (Spain), the Secretaría de Marina of Mexico, and CICESE project 644107, CONACYT 0894PT, and INSU (France). TAM was partially supported by a Royal Society University Research Fellowship. The Department of Geophysics (ICTJA-CSIC) is a Grup dExcellencia de Qualitat (ref. 2001 SGR 00339). We thank C. deMets for providing digital magnetic anomaly picks, and M.A. Gutscher and two anonymous reviewers for constructive comments on an earlier version of this manuscript that contributed significantly to the final version.

\section{References}

[1] K. Wang, R.D. Hyndman, E.E. Davis, Thermal effects of sediment thickening and fluid expulsion in accretionary prisms: model and parameter analysis, J. Geophys. Res. 98 (1993) 9975-9984.

[2] I.J. Ferguson, G.K. Westbrook, M.G. Langseth, G.P. Thomas, Heat flow and thermal models of the Barbados Ridge accretionary complex, J. Geophys. Res. 98 (1993) 4121-4142.

[3] S.C. Singh, T.A. Minshull, G.D. Spence, Velocity structure of a gas hydrate reflector, Science 260 (1993) 204-207.

[4] M.E. MacKay, R.D. Jarrard, G.K. Westbrook, R.D. Hyndman, Origin of bottom simulating reflectors: geophysical evidence from the Cascadia accretionary prism, Geology 22 (1994) 459-462.

[5] M. Yamano, S. Uyeda, Y. Aoki, T.H. Shipley, Estimates of heat flow derived from gas hydrates, Geology 10 (1982) 339-343.

[6] J.J. Dañobeitia, D. Cordoba, L.A. Delgado-Argote, F. Michaud, R. Bartolomé, M. Ferran, R. Carbonell, F. Nuñez-CornuCORTES-P96 Working Group, Expedition gathers new data on crust beneath Mexican west coast, Eos Trans. Am. Geophys. Union 78 (1997) 565-572.

[7] W. Blandy, M. Pardo, Statistical examination of the existence and relative motion of the Jalisco and Southern Mexico blocks, Tectonics 13 (1994) 755-768. 
[8] C. DeMets, S. Traylen, Motion of the Rivera plate since $10 \mathrm{Ma}$ relative to the Pacific and North American plates and the mantle, Tectonophysics 318 (2000) 119-159.

[9] F. Michaud, J.J. Dañobeitia, R. Bartolome, R. Carbonell, L. Delgado-Argote, D. Cordoba, T. Monfret, Did the East Pacific rise subduct beneath the North America plate (western Mexico)? Geo Mar. Lett. 20 (2001) 168-173.

[10] M. Pardo, G. Suárez, Steep subduction geometry of the Rivera plate beneath the Jalisco block in western Mexico, Geophys. Res. Lett. 20 (1993) 2391-2394.

[11] J.C. Moore, T.H. Shipley, Mechanisms of sediment accretion in the Middle America Trench, J. Geophys. Res. 93 (1988) $8911-8927$.

[12] I. Grevemeyer, H. Villinger, Gas hydrate stability and the assessment of heat flow through continental margins, Geophys. J. Int. 145 (2001) 647-660.

[13] G.R. Dickens, M.S. Quinby-Hunt, Methane hydrate stability in seawater, Geophys. Res. Lett. 21 (1994) 2115-2118.

[14] B. Tohidi, A. Danesh, A.C. Todd, Modelling single and mixed electrolyte solutions and its application to gas hydrates, Chem. Eng. Res. Des. 73A (1995) 464-472.

[15] R.D. Hyndman, J.P. Foucher, M. Yamano, A fisher and the scientific team of ocean drilling program Leg 131, Deep-sea bottom simulating reflectors: calibration of the base of the hydrate stability field as used for heat flow estimates, Earth Planet. Sci. Lett. 109 (1992) 289-301.

[16] P. Henry, M. Thomas, M.B. Clennell, Formation of natural gas hydrates in marine sediments 2 . Thermodynamic calculations of stability conditions in porous media, J. Geophys. Res. 104 (1999) 23005-23022.

[17] A. Revil, Thermal conductivity of unconsolidated sediments with geophysical applications, J. Geophys. Res. 105 (2000) $16749-16768$.

[18] T.A. Minshull, R.S. White, Sediment compaction and fluid migration in the Makran accretionary prism, J. Geophys. Res. 94 (1989) 7387-7402.

[19] B. Parsons, J.G. Sclater, An analysis of the variation of ocean floor bathymetry and heat flow with age, J. Geophys. Res. 82 (1977) 803-827.

[20] C.A. Stein, S. Stein, A model for the global variation in oceanic depth and heat flow with lithospheric age, Nature 359 (1992) $123-129$.

[21] A.T. Fisher, K. Becker, Channelised fluid flow in oceanic crust reconciles heat-flow and permeability data, Nature 403 (2000) $71-74$.

[22] E.E. Davis, D.S. Chapman, K. Wang, H. Villinger, A.T. Fisher, S.W. Robinson, J. Grigel, D. Pribnow, J. Stein, K. Becker, Regional heat flow variations across the sedimented Juan de
Fuca Ridge eastern flank: constraints on lithospheric cooling and lateral hydrothermal heat transport, J. Geophys. Res. 104 (1999) $17675-17688$.

[23] I. Hutchison, The effects of sedimentation and compaction on oceanic heat flow, Geophys. J. R. Astron. Soc. 82 (1985) 439-459.

[24] M.D. Langseth, E.A. Silver, The Nicoya convergent margin - a region of exceptionally low heat flow, Geophys. Res. Lett. 23 (1996) 891-894.

[25] C.R. Ranero, J. Phipps Morgan, K. McIntosh, C. Reichert, Bending-related faulting and mantle serpentinisation at the Middle America Trench, Nature 425 (2003) 367-373.

[26] G. Zwart, J.C. Moore, G.R. Cochrane, Variations in temperature gradients identify active faults in the Oregon accretionary prism, Earth Planet. Sci. Lett. 139 (1996) 485-495.

[27] C.A. Stein, Heat flow and flexure at subduction zones, Geophys. Res. Lett. 30 (2003) 2197, doi:10.1029/2003GL018478.

[28] A.T. Fisher, C.A. Stein, R.N. Harris, K. Wang, E.A. Silver, M. Pfender, M. Hutnak, A. Cherkaoui, R. Bodzin, H. Villinger, Abrupt thermal transition reveals hydrothermal boundary and role of seamounts within the Cocos plate, Geophys. Res. Lett. 30 (2003) 1550, doi:10.1029/2002GL016766.

[29] P. Molnar, P. England, Temperatures, heat flux and frictional stress near major thrust faults, J. Geophys. Res. 95 (1990) $4833-4856$.

[30] I. Grevemeyer, J.L. Diaz-Naveas, C.R. Ranero, H.W. Villinger, Ocean Drilling Program Leg 202 Scientific Party, Heat flow over the descending Nazca plate in central Chile, $32^{\circ} \mathrm{S}$ to $41^{\circ} \mathrm{S}$ : observations from ODP Leg 202 and the occurrence of natural gas hydrates, Earth Planet. Sci. Lett. 213 (2003) 285-298.

[31] J.P. Ziagos, D.D. Blackwell, F. Mooser, Heat flow in southern Mexico and the thermal effects of subduction, J. Geophys. Res. 90 (1985) 5410-5420.

[32] C.A. Currie, R.D. Hyndman, K. Wang, V. Kostoglodov, Thermal models of the Mexico subduction zone: implications for the megathrust seismogenic zone, J. Geophys. Res. 107 (2002) 2370, doi:10.1029/2001JB000886.

[33] D. Davis, J. Suppe, F.A. Dahlen, Mechanics of fold-and-thrust belts and accretionary wedges, J. Geophys. Res. 88 (1983) 1153-1172.

[34] M.-A. Gutscher, N. Kukowski, J. Malaveille, S. Lallemand, Episodic imbricate thrusting and underthrusting: analog experiments and mechanical analysis applied to the Alaskan accretionary wedge, J. Geophys. Res. 103 (1998) 10161-10176.

[35] C. Ruppel, Anomalously cold temperatures observed at the base of the gas hydrate stability zone on the U.S Atlantic passive margin, Geology 25 (1997) 699-702. 